\title{
Interfacial Effects During Thermal Cycling of Cu-Filled Through-Silicon Vias (TSV)
}

\author{
P. KUMAR, ${ }^{1}$ I. DUTTA, ${ }^{1,3}$ and M.S. BAKIR ${ }^{2}$ \\ 1.-School of Mechanical \& Materials Engineering, Washington State University, Pullman, \\ WA 99164, USA. 2.-School of Electrical and Computer Engineering, Georgia Institute of Tech- \\ nology, Atlanta, GA 30332, USA. 3.—e-mail: idutta@wsu.edu
}

\begin{abstract}
Large shear stresses may develop at interfaces between dissimilar materials during thermal excursions when there is a significant difference in their coefficients of thermal expansion. The shear stress may cause interfaces to slide via diffusional process, thereby accommodating the relative dimensional changes between the two materials. This phenomenon presents a significant reliability issue in three-dimensional (3-D) interconnect structures involving through-silicon vias (TSVs), which are subjected not only to continuous thermal cycling but also to large electric current densities during service. This paper reports experimental evidence of interfacial sliding between $\mathrm{Cu}$ and $\mathrm{Si}$ in Cu-filled TSVs during thermal cycling conditions, and in the presence of electric current. Two different thermal cycling conditions were used: (i) small $\Delta T$ thermal cycling $\left(-25^{\circ} \mathrm{C}\right.$ to $\left.135^{\circ} \mathrm{C}\right)$ and (ii) large $\Delta T$ thermal cycling $\left(25^{\circ} \mathrm{C}\right.$ to $425^{\circ} \mathrm{C}$ ). Prior to thermal cycling, a few $\mathrm{Cu}$-filled TSV samples were annealed for $30 \mathrm{~min}$ at $425^{\circ} \mathrm{C}$. Cu intruded inside $\mathrm{Si}$ in nonannealed samples during small $\Delta T$ thermal cycling, whereas protrusion of $\mathrm{Cu}$ relative to $\mathrm{Si}$ occurred during all other thermal excursions. Application of electric current biased the net displacement of the $\mathrm{Cu}$ in the direction of electron flow, leading to enhanced protrusion (or intrusion) of $\mathrm{Cu}$ relative to the thermal cycling only (i.e., without electric current) condition. A simple one-dimensional analytical model and associated numerical simulations are utilized to rationalize the experimental observations.
\end{abstract}

Key words: Through-silicon via, interfacial sliding, thermal cycling, 3-D packaging, electromigration

\section{INTRODUCTION}

The coefficient of thermal expansion (CTE) mismatch between the constituent materials of a multicomponent system typically results in significant interfacial shear stresses near the extremities of the composite during a thermal excursion. Examples include fiber-reinforced composites, ${ }^{1,2}$ thin-film interconnect lines embedded in low- $k$ dielectric structures in the back-end of microelectronic devices, ${ }^{3-6}$ as well as $\mathrm{Cu}$-filled through-silicon vias (TSVs). ${ }^{7-9}$ If the thermal excursion is conducted at a

(Received April 28, 2011; accepted July 20, 2011;

published online August 10, 2011) relatively slow rate, the thermally induced stresses which build up in each component can be relieved via creep and/or plasticity, and interfacial fracture may be avoided altogether. ${ }^{1}$ Instead, interfacial shear stresses can induce diffusionally driven interfacial sliding (IS), which accommodates differential deformation of the two adjacent components without breaking interfacial bonds. ${ }^{1,10-12}$ Indeed, interfacial sliding has been reported to cause protrusion or intrusion of graphite fibers in an Al-based composite $^{1,2}$ and relative displacement of the thinfilm deposits with respect to substrates or surrounding media ${ }^{3-6,13}$ during thermal cycling.

The kinetics of stress-driven interfacial sliding is given as follows: ${ }^{11}$ 


$$
\dot{U}=\frac{C \delta_{\mathrm{i}} D_{\mathrm{i}} \Omega}{k T h^{2}}\left[\tau_{\mathrm{i}}+2 \pi^{3}\left(\frac{h}{\lambda}\right)^{3} \sigma_{\mathrm{n}}\right],
$$

where $C$ is a numerical constant, $\delta_{\mathrm{i}}$ and $D_{\mathrm{i}}$ are the interfacial thickness and diffusivity, respectively, $\Omega$ is the atomic volume of the diffusing species, $\lambda$ and $h$ are the periodicity and roughness of the interface, respectively, $k$ and $T$ are the Boltzmann constant and temperature, respectively, and $\tau_{\mathrm{i}}$ and $\sigma_{\mathrm{n}}$ are the interfacial shear stress and the far-field normal stress, respectively. The interfacial shear stress, $\tau_{\mathrm{i}}$, is the driving force for this process, which is enhanced if a far-field tensile normal interfacial stress $\sigma_{\mathrm{n}}$ is present (i.e., positive $\sigma_{\mathrm{n}}$ ), or reduced if there is a compressive $\sigma_{\mathrm{n}}$ (negative $\sigma_{\mathrm{n}}$ ). The effect of $\sigma_{\mathrm{n}}$ on sliding is finite only when $\tau_{\mathrm{i}}$ is nonzero, and $U=0$ when $\tau_{\mathrm{i}}=0$ even if $\sigma_{\mathrm{n}}$ is nonzero. Since interfacial sliding is a diffusion-controlled phenomenon, it becomes significant only at high temperatures.

Another fundamental characteristic of interfacial sliding is that its kinetics may be affected by electromigration (EM), since both are diffusionally driven, particularly when the interfaces, rather than grain boundaries, provide the primary short-circuit path for the EM flux (i.e., when the grain size is relatively large). ${ }^{14}$ It was shown that, depending on the direction of electric current relative to the applied $\tau_{\mathrm{i}}$, the interfacial sliding can either increase or decrease, or even directionally reverse, relative to sliding under $\tau_{\mathrm{i}}$ only. ${ }^{14}$ The following gives the kinetics of the electromigration-assisted interfacial sliding (EM-assisted IS) in the absence of far-field normal stress and for the conditions where the interfaces act as the major route for the diffusional flux: ${ }^{14}$

$$
\dot{U}=\frac{8 \Omega \delta_{\mathrm{i}} D_{\mathrm{i}}}{k T h^{2}} \tau_{\mathrm{i}}+\frac{4 \delta_{\mathrm{i}} D_{\mathrm{i}}}{k T h} Z^{*} e E,
$$

where $Z^{*}, e$, and $E$ are the effective charge number of the diffusing atom, the free charge of an electron, and the applied electric field, respectively. An important characteristic of EM-assisted IS, as revealed through Eq. (2), is that the effects of the shear stress and the electromigration on the interfacial sliding can be linearly superimposed. Hence, based on Eqs. (1) and (2), the kinetics of EM-assisted IS in the presence of far-field normal stress can be given as

$$
\dot{U}=\frac{8 \delta_{\mathrm{i}} D_{\mathrm{i}} \Omega}{k T h^{2}}\left[\tau_{\mathrm{i}}+2 \pi^{3}\left(\frac{h}{\lambda}\right)^{3} \sigma_{\mathrm{n}}\right]+\frac{4 \delta_{\mathrm{i}} D_{\mathrm{i}}}{k T h} Z^{*} e E .
$$

In stacked-die packages, a TSV in a given die connects to a back-end of line (BEOL) stack at one end, and $\mathrm{Cu}$ pillars for connecting to other dies through solder microbumps at the opposite end. The CTE mismatch between $\mathrm{Cu}\left(\alpha_{\mathrm{Cu}} \approx 17 \times 10^{-6} \mathrm{~K}^{-1}\right)$ and $\mathrm{Si}\left(\alpha_{\mathrm{Si}} \sim 3 \times 10^{-6} \mathrm{~K}^{-1}\right)$ is significant, and the microelectronic packages continuously undergo thermal cycling, which make Cu-filled TSVs prone to interfacial sliding. Even a slight intrusion or protrusion of the TSVs would place the delicate BEOL structure and the brittle intermetallic compound (IMC)-rich microbumps in tension or compression, making them prone to distortion and fracture, particularly when adjacent TSVs protrude or intrude by different amounts depending on the direction and magnitude of current carried by each. As TSVs become finer and packages become more vertically integrated, simultaneously raising the thermal, mechanical, and electrical loads ${ }^{15}$ these effects will become more egregious. Therefore, it is imperative to study the effects of interfacial incompatibilities on the integrity of TSVs.

To date, only one analytical study has investigated interfacial incompatibility in TSVs due to interfacial fracture, assuming that the $\mathrm{Cu}$ deforms elastically only. ${ }^{7}$ This forces the stresses in the $\mathrm{Cu}$ to rise to very high levels, and produces conditions suitable for interfacial fracture. In reality, these conditions will be valid during thermal shock (very rapid thermal cycling) only. During slow thermal cycling, creep/plasticity effects will limit stresses, and given sufficient time during heating, cooling, and dwell, will drive interfacial diffusional fluxes to accommodate the differential deformation between $\mathrm{Cu}$ and $\mathrm{Si}$ via interfacial sliding. ${ }^{12,14}$ Indeed, the importance of plastic flow in $\mathrm{Cu}$ vias is well known in the phenomenon known as "Cu pumping," which occurs during temperature excursions associated with BEOL processes. ${ }^{16}$ Therefore, it is necessary to incorporate creep and plasticity of $\mathrm{Cu}$ while analyzing the response of $\mathrm{Cu}$-filled TSVs to a thermal excursion. However, there exists no report in the literature which has addressed the effect of slow thermal cycling on the integrity of TSVs, while accounting for creep, plasticity, interfacial sliding, and electromigration.

Accordingly, the goals of this paper are: (i) to study the effect of slow thermal cycling, hence allowing creep, plasticity, and interfacial sliding to occur, on the integrity of Cu-filled TSVs, and (ii) to study the effect of electric current (electromigration) on the net protrusion or intrusion of $\mathrm{Cu}$ relative to Si. Also, an existing model ${ }^{1,10}$ is modified to include the effects of electromigration and to explain the experimental trends.

\section{EXPERIMENTAL PROCEDURES}

Figure 1 shows a schematic of a Cu-filled TSV. A few such samples were annealed at $425^{\circ} \mathrm{C}$ for 30 min in a vacuum furnace operating at $10^{-4}$ Torr vacuum. Annealing was conducted to increase grain size and to relieve residual stresses in $\mathrm{Cu}$, which has often been reported to be beneficial against $\mathrm{Cu} / \mathrm{Si}$ interface fracture as well as for the electronic performance of devices in the vicinity of TSVs (private communication with IBM). Samples were 


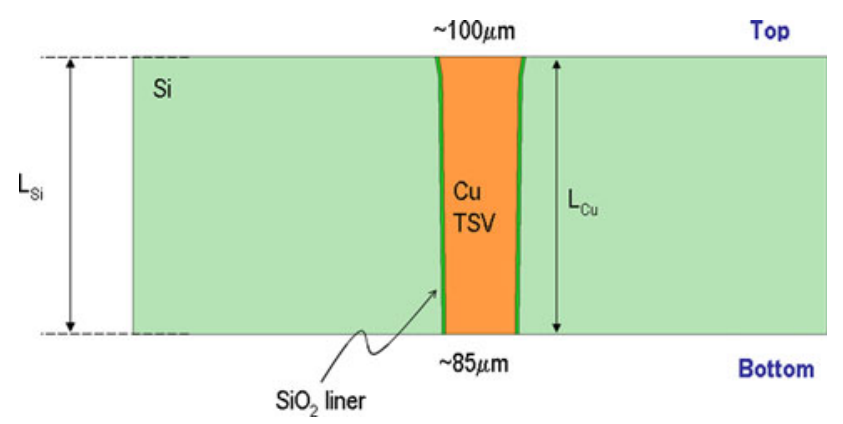

Fig. 1. Schematic of a Cu-filled TSV.

exposed to various numbers of cycles of two kinds of thermal cycling: (i) small $\Delta T$ thermal cycling: from $-25^{\circ} \mathrm{C}$ to $135^{\circ} \mathrm{C}$ at $\sim 0.1^{\circ} \mathrm{C} / \mathrm{s}$ in a thermal cycling chamber, and (ii) large $\Delta T$ thermal cycling: from $25^{\circ} \mathrm{C}$ to $425^{\circ} \mathrm{C}$ at $\sim 0.02^{\circ} \mathrm{C} / \mathrm{s}$ in a vacuum furnace operating at $10^{-4}$ Torr vacuum.

Electric current, corresponding to current density of $5.22 \times 10^{4} \mathrm{~A} / \mathrm{cm}^{2}$, was passed through Cu pillars of a few of the TSV samples undergoing large $\Delta T$ thermal cycling. The electric current was passed in a direction so that the flow of electrons and the interfacial shear stress were parallel.

All samples were observed by scanning electron microscopy (SEM), before and after thermoelectrical excursions. SEM micrographs from the same place were taken from the same angle for direct comparison. A few samples, in conditions of as-fabricated, after annealing, and after three cycles of large $\Delta T$ thermal cycling, were metallographically polished to reveal the cross-sectional features, and to study the evolution in the $\mathrm{Cu}$ microstructure and the $\mathrm{Cu}$ / Si interface during thermal excursions.

\section{MODEL}

Dutta ${ }^{1}$ presented a one-dimensional model for the axial strain response of continuous fiber composites during axial creep, accounting for interfacial sliding due to the presence of interfacial shear stresses near the end of the fiber. The model was developed for a composite system with thermoelastic fiber and thermoelastoplastic creeping matrix and was able to predict protrusion as well as intrusion of fiber (graphite) relative to matrix (an $\mathrm{Al}$ alloy). ${ }^{1}$ Here, the model is slightly modified to suit current-carrying, Cu-filled TSVs by accounting for: (i) thermoelastoplastic creeping fiber $(\mathrm{Cu})$, (ii) thermoelastic matrix (Si), and (iii) electromigration. The details of the steps to derive the model are available in Refs. 1,10, whereas here, an outline highlighting the important steps and the solution scheme to incorporate electromigration will be presented.

A schematic of the interfacial region, as conceptualized for the model, is shown in Fig. 2. During thermal cycling, a shear stress $\tau_{\mathrm{i}}$ is generated which varies along the axial coordinate $z$. $\tau_{\mathrm{i}}$ is zero at the center of $\mathrm{Cu}(z=0)$ and maximum at the end of the

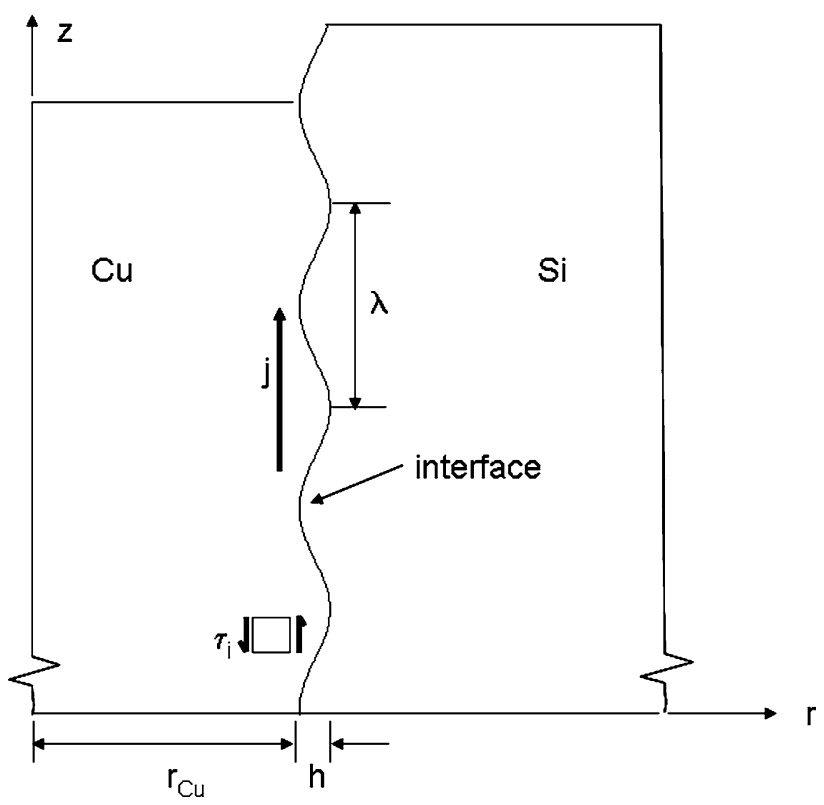

Fig. 2. Schematic of the $\mathrm{Cu} / \mathrm{Si}$ interfacial region used in modeling, showing a periodic interface with width of $h$ and periodicity of $\lambda$. The axial coordinate is zero at the middle of the $\mathrm{Cu}$ length, and the radial coordinate $r$ is zero at the middle of the Cu diameter.

$\mathrm{Cu}$ pillar (i.e., $z=l_{\mathrm{Cu}} / 2$ ). Along with the $\tau_{\mathrm{i}}$, which varies with temperature (i.e., during a thermal cycle) and with $z$, an electric current with constant density, equal to $j$, is assumed to flow along the $+z$ direction. The following two assumptions are made for simplicity: (i) interface is the dominant route for the diffusional flux due to the electromigration, and (ii) the effect of the radial stresses, akin to $\sigma_{\mathrm{n}}$, generated during thermal cycling due to the CTE mismatch between $\mathrm{Cu}$ and $\mathrm{Si}$ on interfacial sliding is negligible. Based on Eq. (2), the interfacial shear strain rate can be given as

$$
\dot{\gamma}_{\mathrm{i}}=\dot{\gamma}_{\mathrm{i}, \tau}+\dot{\gamma}_{\mathrm{i}, \mathrm{EM}}=A_{\mathrm{i}} \tau_{\mathrm{i}}+B_{\mathrm{i}, \mathrm{EM}} Z^{*} e E,
$$

where subscripts " $\tau$ " and "EM" indicate interfacial shear stress and electromigration, respectively, and $A_{\mathrm{i}}$ and $B_{\mathrm{i}, \mathrm{EM}}$ are given as

$$
\begin{gathered}
A_{\mathrm{i}}=\frac{8 \delta_{\mathrm{i}} D_{\mathrm{i}} \Omega}{k T h^{3}}, \\
B_{\mathrm{i}, \mathrm{EM}}=\frac{4 \delta_{\mathrm{i}} D_{\mathrm{i}}}{k T h^{2}} .
\end{gathered}
$$

When $\mathrm{Si}$ and $\mathrm{Cu}$ are in nonisostrain condition, the stress equilibrium under a constant applied stress $\sigma_{\mathrm{a}}$ requires that ${ }^{10}$

$$
\sigma_{\mathrm{a}}=\sigma_{\mathrm{Cu}} V_{\mathrm{Cu}}\left[\frac{1+\bar{\varepsilon}_{\mathrm{Si}}}{1+\bar{\varepsilon}_{\mathrm{Cu}}}\right]+\sigma_{\mathrm{Si}} V_{\mathrm{Si}}
$$


where $\sigma_{\mathrm{Cu}}$ and $\sigma_{\mathrm{Si}}$ are the axial stress in $\mathrm{Cu}$ and $\mathrm{Si}$, respectively, $V_{\mathrm{Cu}}$ and $V_{\mathrm{Si}}$ are the volume fractions of $\mathrm{Cu}$ and $\mathrm{Si}$, respectively, and $\bar{\varepsilon}_{\mathrm{Cu}}$ and $\bar{\varepsilon}_{\mathrm{Si}}$ are the average axial strains of the $\mathrm{Cu}$ and $\mathrm{Si}$, respectively.

Strain continuity across the interface requires that $^{1,10}$

$$
v=u+w,
$$

where $v, u$, and $w$ are the displacements in $\mathrm{Cu}, \mathrm{Si}$, and interface, respectively. Differentiating Eq. (7) with respect to $z$ gives

$$
\frac{l_{0}}{2}\left(\bar{\varepsilon}_{\mathrm{Cu}}-\bar{\varepsilon}_{\mathrm{Si}}\right)=h \gamma_{\mathrm{i}, \tau},
$$

where $l_{0}$ is the nominal gauge length (the shorter of the $\mathrm{Cu}$ and $\mathrm{Si}$ lengths), $\bar{\varepsilon}_{\mathrm{Cu}}$ and $\bar{\varepsilon}_{\mathrm{Si}}$ represent average axial strain values over half the gauge length $(z=0$ to $l_{0} / 2$ ), and $\gamma_{\mathrm{i}, \tau}$ is the interfacial shear strain at $z=l_{0} / 2$ only due to the applied interfacial shear stress, given by ${ }^{1}$

$$
\gamma_{\mathrm{i}, \tau}=\dot{\gamma}_{\mathrm{i}, \tau} t=A_{\mathrm{i}} \tau_{\mathrm{i}, \mathrm{at} t}=l_{0} / 2 t
$$

It is important to note that, even though the interfacial shear strain is affected by the electromigration, the interfacial sliding due to electromigration is uniform throughout the length of the $\mathrm{Cu}$ and hence electromigration does not explicitly cause any strain in the $\mathrm{Cu}$ and Si. Accordingly, the continuity relationship in presence of electromigration, as given by Eq. (8), is identical to the situation where only $\tau_{\mathrm{i}}$ is present. Nevertheless, at any instance, the electromigration biases the displacement of the entire $\mathrm{Cu}$ pillar in one direction, meaning that, unlike the pure thermal cycling condition where the displacement of $\mathrm{Cu}$ relative to $\mathrm{Si}$ is symmetric across the center of $\mathrm{Cu}$ (i.e., $z=0$ ), thermal cycling with electric current results in a net shift of $\mathrm{Cu}$ pillar along the direction of electron flow in addition to the symmetric effects of $\tau_{\mathrm{i}}$. This is because the value of $w$ (Eq. (7)), which is the summation of the effects of $\tau_{\mathrm{i}}$ (symmetric across $z=0$ ) and electromigration (unidirectional, nonsymmetric), is different above and below $z=0 .{ }^{14}$ Since electromigration results in a change in the length of $\mathrm{Cu}$ inside $\mathrm{Si}$ as compared with the situation where sliding is due to $\tau_{\mathrm{i}}$ only, the stress/strain state in $\mathrm{Cu}$ and $\mathrm{Si}$ changes in the next iteration. The steps taken to account for this will be explained later while discussing computer program execution steps.

Assuming that diffusional creep is the dominant creep mechanism under the given temperature and stress regimes, the strain in $\mathrm{Cu}$ and $\mathrm{Si}$ is given by ${ }^{1,10}$

$$
\begin{aligned}
& \bar{\varepsilon}_{\mathrm{Cu}}=\bar{\varepsilon}_{\mathrm{Cu}}^{\mathrm{th}}+\bar{\varepsilon}_{\mathrm{Cu}}^{\mathrm{el}}+\bar{\varepsilon}_{\mathrm{Cu}}^{\mathrm{pl}}+\bar{\varepsilon}_{\mathrm{Cu}}^{\mathrm{cr}} \\
& =\int_{T_{1}}^{T_{2}} \alpha_{\mathrm{Cu}} \mathrm{d} T+\frac{\sigma_{\mathrm{Cu}}}{E_{\mathrm{Cu}}}+\left(\frac{\sigma_{\mathrm{Cu}}-\sigma_{\mathrm{Cu}}^{\mathrm{YS}}}{K_{1}}\right)^{1 / n_{1}}+A_{\text {diff }} \sigma_{\mathrm{Cu}}(10 \mathrm{a})
\end{aligned}
$$

and

$$
\bar{\varepsilon}_{\mathrm{Si}}=\bar{\varepsilon}_{\mathrm{Si}}^{\mathrm{th}}+\bar{\varepsilon}_{\mathrm{Si}}^{\mathrm{el}}=\int_{T_{1}}^{T_{2}} \alpha_{\mathrm{Si}} \mathrm{d} T+\frac{\sigma_{\mathrm{Si}}}{E_{\mathrm{Si}}},
$$

where the superscripts "th," "el," "pl," and "cr" indicate thermal, elastic, plastic, and creep components, respectively, $T_{1}$ and $T_{2}$ are the lower and upper limits of temperature during a thermal excursion, $\alpha$ and $E$ are the CTE and Young's modulus, respectively, $K_{1}$ and $n_{1}$ are the work-hardening coefficient and exponent, respectively, and $A_{\text {diff }}$ is the effective coefficient for diffusional creep, given as

$$
A_{\text {diff }}=\frac{14 \Omega}{k T d^{2}}\left[\left(\frac{\pi}{d}\right) \delta_{\mathrm{gb}} D_{\mathrm{gb}}+D_{\mathrm{L}}\right],
$$

where $d$ is the $\mathrm{Cu}$ grain size, $\delta_{\mathrm{gb}}$ is the effective thickness of the grain boundary, $D_{\mathrm{gb}}$ is the grain boundary diffusivity, and $D_{\mathrm{L}}$ is the volume diffusivity.

Rewriting Eq. (8) in incremental form and substituting for $\bar{\varepsilon}_{\mathrm{Cu}}, \bar{\varepsilon}_{\mathrm{Si}}$, and $\gamma_{\mathrm{i}, \tau}$ using Eqs. 8-10 and assuming that the externally applied axial stress on TSV during thermal cycling is equal to zero yields

$\left.\Delta \sigma_{\mathrm{Cu}}=-\left[\frac{\left(\alpha_{\mathrm{Cu}}-\alpha_{\mathrm{Si}}\right) \Delta T+\Delta \varepsilon_{\mathrm{Cu}}^{\mathrm{cr}}+\frac{2 h}{l_{0}} A_{\mathrm{i}} \tau_{\mathrm{i}\left(z=l_{0} / 2\right)} \Delta t}{\frac{V_{\mathrm{Cu}}}{E_{\mathrm{Si}} V_{\mathrm{Si}}}\left(\frac{1+\bar{\varepsilon}_{\mathrm{Si}}}{1+\overline{\mathrm{C}}_{\mathrm{Cu}}}\right)+\frac{1}{E_{\mathrm{Cu}}}+\frac{1}{K_{1} n_{1}}\left(\frac{K_{1}}{\sigma_{\mathrm{Cu}}-\sigma_{\mathrm{Cu}}^{\mathrm{YS}}}\right)}\right)^{\left(n_{1}-1\right) / n_{1}}\right]$,

where superscript "YS" indicates yield point.

The interfacial shear stress can be calculated as a function of $z$ by using a modified shear lag approach after incorporating the effects of plasticity and creep in $\mathrm{Cu}$, and is given by ${ }^{1,10}$

$$
\tau_{\mathrm{i}}=-\frac{r_{\mathrm{Cu}}}{2} B_{1} \sqrt{\frac{H_{1}}{E_{\mathrm{Si}}}} \sinh \left(\sqrt{\frac{H_{1}}{E_{\mathrm{Si}}}} z\right) \quad \text { for } z<z_{0},
$$

and

$$
\tau_{\mathrm{i}}=A_{0}+\left(\tau_{\mathrm{Cu}}{ }^{\mathrm{YS}}-A_{0}\right)\left(\frac{z}{z_{0}}\right)^{1 / B_{0}} \text { for } z \geq z_{0},
$$

where $r_{\mathrm{Cu}}$ is the radius of $\mathrm{Cu}$, and the parameters $H_{1}, B_{1}, A_{0}$, and $B_{0}$ are given as follows:

$$
\begin{gathered}
H_{1}=\frac{2}{r_{\mathrm{Cu}}(N+M)}, \\
B_{1}=-\frac{E_{\mathrm{Si}} \bar{\varepsilon}_{\mathrm{Cu}}}{\left(\frac{1}{E_{\mathrm{Cu}}}+A_{\text {diff }}\right) \cosh \left(\frac{\beta l_{0}}{2}\right)},
\end{gathered}
$$


(a)

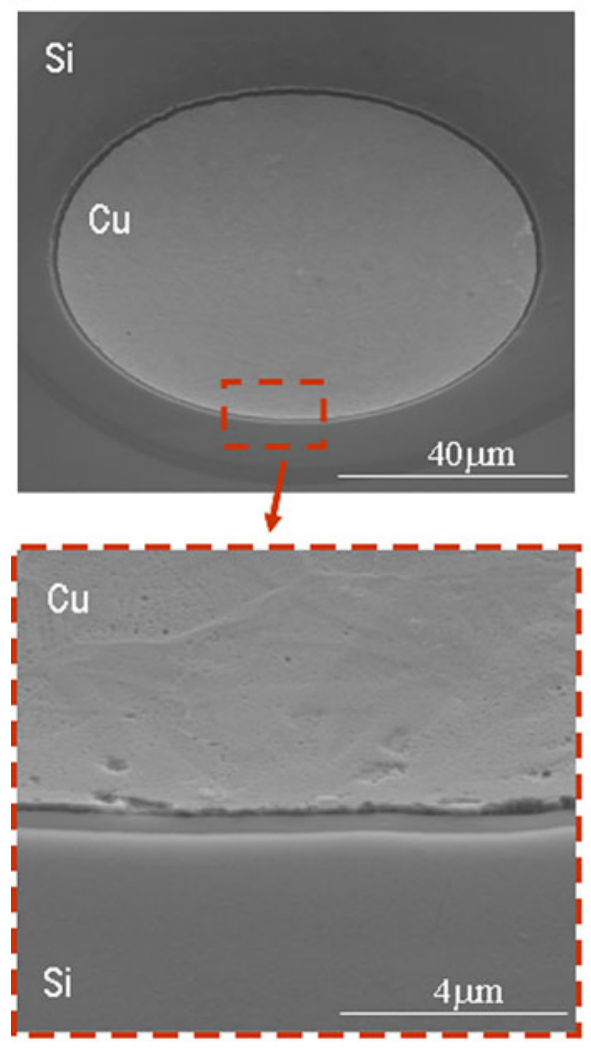

(b)

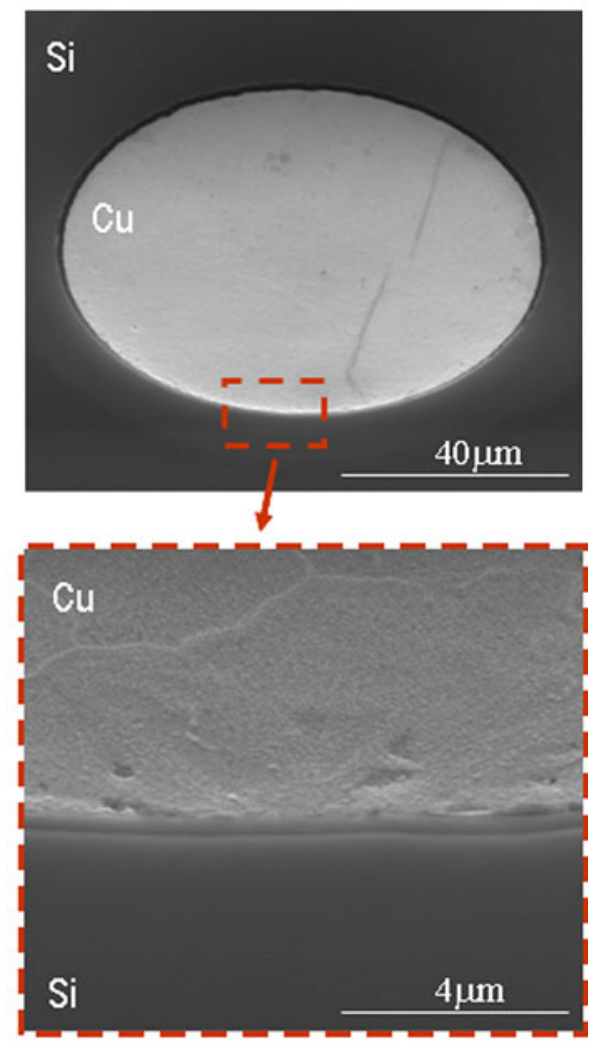

(c)

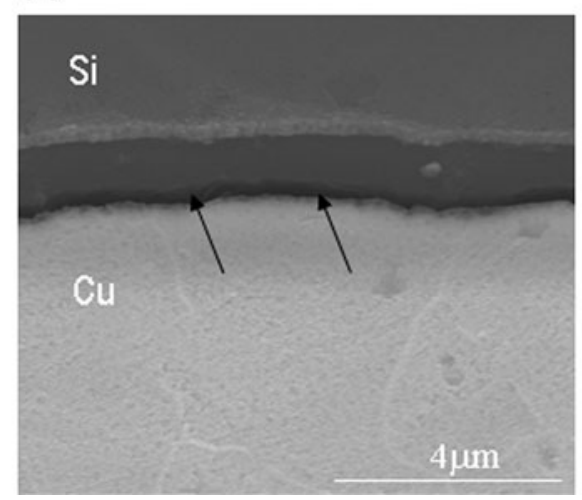

Fig. 3. The effect of small $\Delta T$ thermal cycling on nonannealed Cu-filled TSV samples: (a) as-fabricated samples, (b) after 20 cycles between $-25^{\circ} \mathrm{C}$ and $135^{\circ} \mathrm{C}$ at $\sim 0.1^{\circ} \mathrm{C} / \mathrm{s}$, and (c) after 20 small $\Delta T$ thermal cycles from a region of the sample showing the $\mathrm{SiO}_{2}$ liner wall. Arrows show the vertical portion of the liner wall, where $\mathrm{Cu}$ has slid down.

$$
\begin{gathered}
A_{0}=\sigma_{\mathrm{Cu}} \mathrm{YS}\left(1-\frac{K_{1}}{E_{\mathrm{Cu}}}\right), \\
B_{0}=\frac{K_{1}}{h}(N+M),
\end{gathered}
$$

where $N=\left(r_{\mathrm{Cu}} / G_{\mathrm{Si}}\right) \ln \left(R / r_{\mathrm{Cu}}\right), M=h A_{\mathrm{i}} t, R=r_{\mathrm{Cu}} /$ $\sqrt{V_{\mathrm{Cu}}}$, and $\beta=\sqrt{H_{1}\left(1 / E_{\mathrm{Cu}}+A_{\text {diff }}\right)}$

The basic solution procedure to obtain the stress/ strain state of the $\mathrm{Cu}$ and Si during a thermoelectrical

excursion consists of: (1) calculating the initial stress state in $\mathrm{Cu}, \sigma_{\mathrm{Cu}, 0}$, at the start of thermal cycling; (2) calculating the incremental stress change $\Delta \sigma_{\mathrm{Cu}}$ using Eq. (12); (3) updating the stress in $\mathrm{Cu}$ as $\sigma_{\mathrm{Cu}, k+1}=\sigma_{\mathrm{Cu}, k}+\Delta \sigma_{\mathrm{Cu}}$ (here the subscript " $k$ " represents the $k$ th solution step); (4) computing the $\mathrm{Cu}$ and Si strain components using Eq. (10); (5) updating the length of $\mathrm{Cu}$ above $z=O$ (i.e., at $z>0$ ) by adding the displacement due to electromigration, equal to $B_{\mathrm{i}, \mathrm{EM}} Z^{*} e E \Delta t$, to the topmost axial coordinate of $\mathrm{Cu}$ (i.e. , $z=l_{0} / 2$ ); and then (6) adjusting the length of $\mathrm{Cu}$ (i.e., $l_{0} / 2$ ) inside $\mathrm{Si}$ over which $\tau_{\mathrm{i}}$ and $\sigma_{\mathrm{Cu}}$ are calculated in next step. This procedure is 
(a)
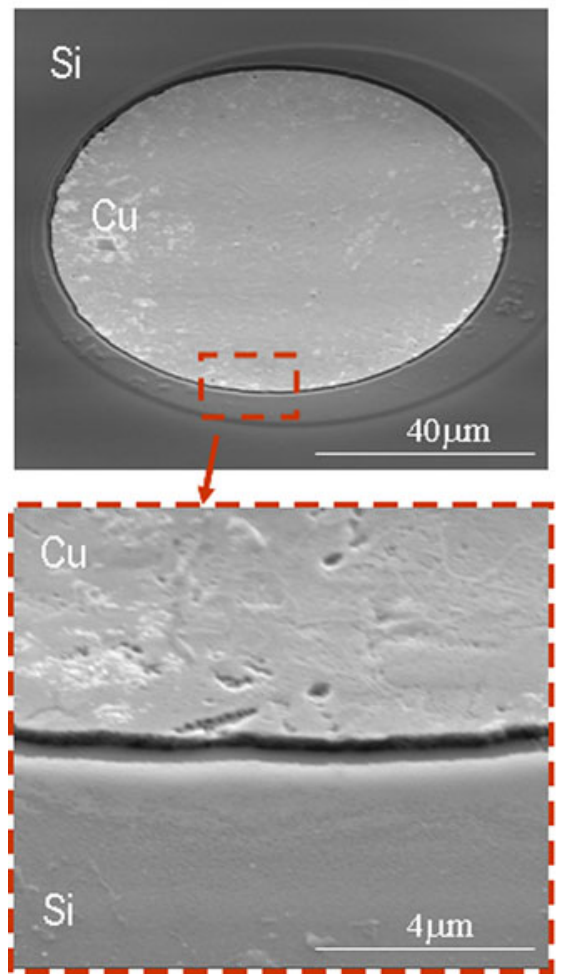

(b)

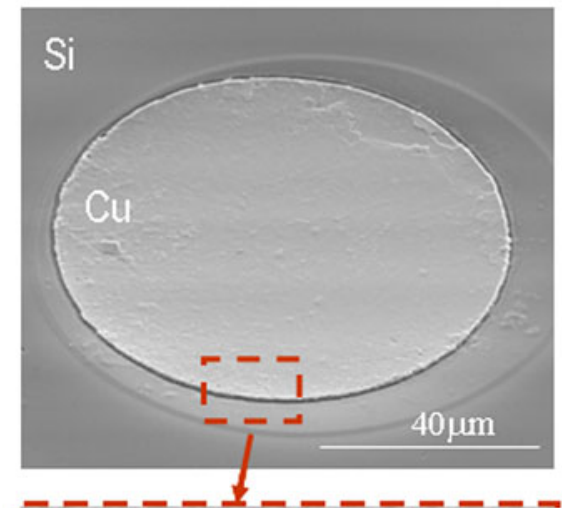

(c)

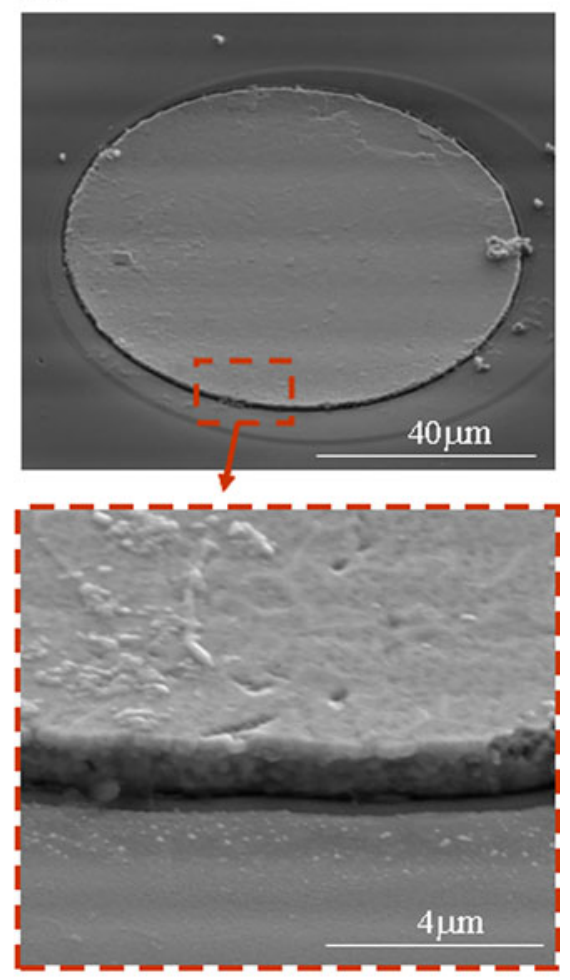

Fig. 4. The effect of annealing and small $\Delta T$ thermal cycling on Cu-filled TSV samples: (a) as fabricated, (b) after 30 min of annealing at $425^{\circ} \mathrm{C}$, and (c) after 20 cycles between $-25^{\circ} \mathrm{C}$ and $135^{\circ} \mathrm{C}$.

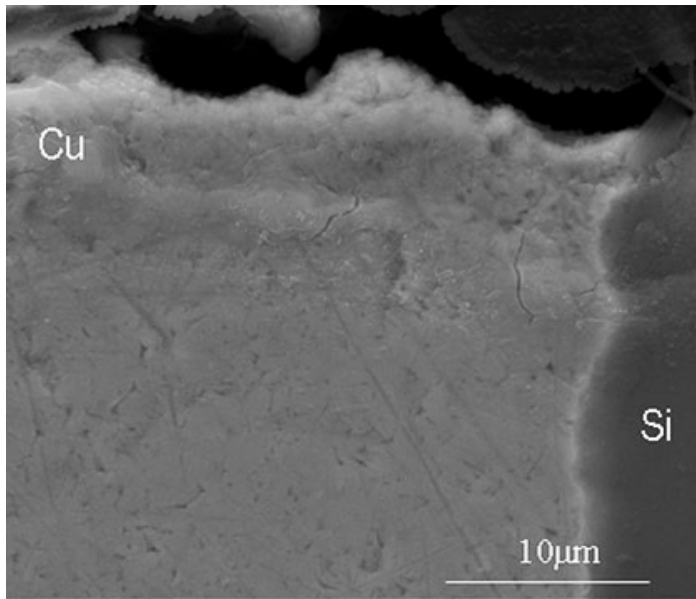

Fig. 5. Cross-sectional micrograph, showing the top edge of the Cu-filled TSVs following annealing at $425^{\circ} \mathrm{C}$ for $30 \mathrm{~min}$.

utilized iteratively, allowing the temperature and time to change incrementally. At each solution step, the stress and strain increments are calculated and the $z$-coordinate of the topmost point of $\mathrm{Cu}$ and $\mathrm{Si}$ are updated. A computer program was written in MATLAB to conduct the above iterative computations.

\section{RESULTS AND DISCUSSION}

Figure 3 shows the effect of the small $\Delta T$ thermal cycling on a nonannealed sample. Comparison of high-magnification pictures from the same region clearly shows that the $\mathrm{Cu}$ has intruded after 20 small $\Delta T$ thermal cycles. SEM micrographs from different locations, as shown in Fig. 3c, revealed a clean $\mathrm{SiO}_{2}$ liner wall, free from any leftover $\mathrm{Cu}$, indicating interfacial fracture-free intrusion of the $\mathrm{Cu}$ solely due to the diffusion-assisted interfacial sliding. Intrusion of $\mathrm{Cu}$ (high $\alpha$, thermoelastoplastic creeping component) inside Si (low $\alpha$, thermoelastic component), as observed in these TSV samples during small $\Delta T$ thermal cycling, is analogous to the intrusion of graphite fibers (low $\alpha$, thermoelastic component) in an Al-based composite (high $\alpha$, thermoelastoplastic creeping component) during large $\Delta T$ thermal cycling. ${ }^{1}$

Figure 4 shows the effect of annealing on the Cu-filled TSV samples. As shown in Fig. 4a, b, the $\mathrm{Cu}$ protrudes out of Si following annealing. Figure 5 shows the cross-section of the sample near the extremities of the $\mathrm{Cu}$ where the shear stresses generated due to CTE mismatch are maximum. Figure 5 clearly shows that the interface between $\mathrm{Cu}$ and $\mathrm{Si}$ did not fracture during annealing and the protrusion, as shown in Fig. 4, was due to 
(a)

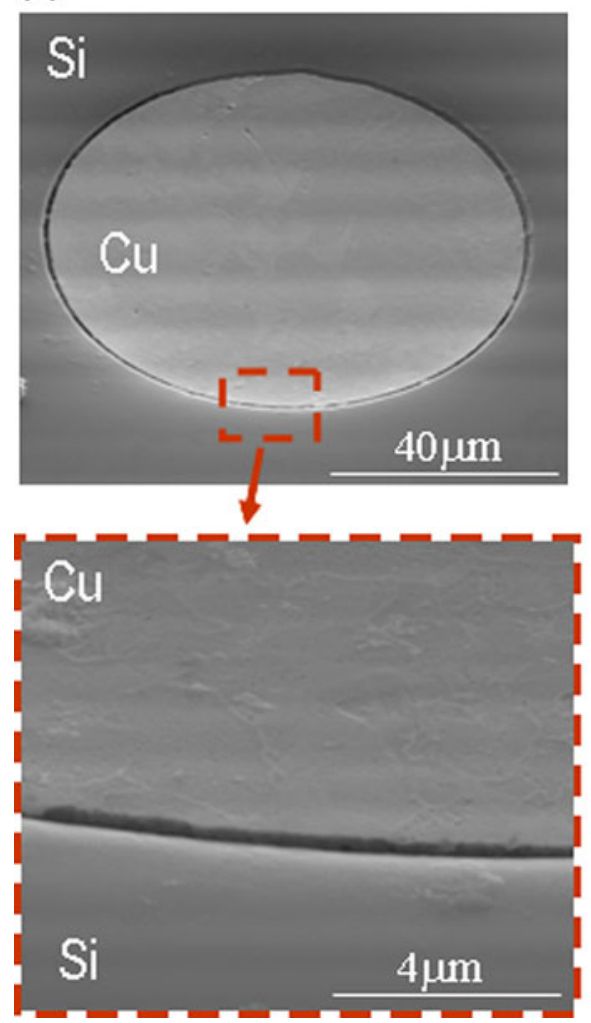

(b)

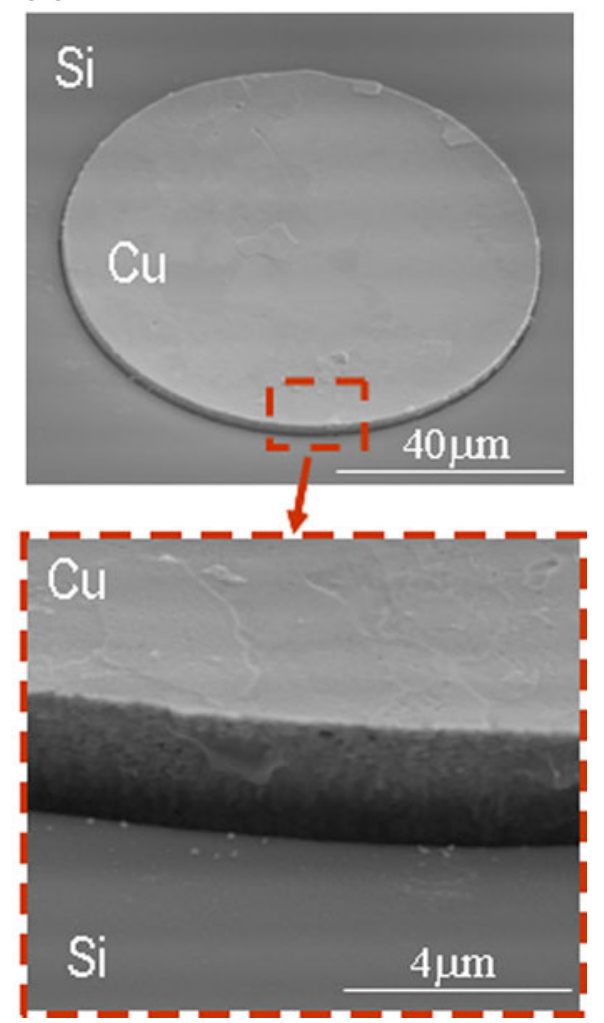

Fig. 6. Effect of large $\Delta T$ thermal cycling on nonannealed Cu-filled TSV samples: (a) as fabricated, and (b) after three cycles between $25^{\circ} \mathrm{C}$ and $425^{\circ} \mathrm{C}$ at $\sim 0.02^{\circ} \mathrm{C} / \mathrm{s}$.

diffusion-assisted interfacial sliding. Annealing acts as one high $\Delta T$ thermal cycle with a long dwell time at the maximum temperature. As will be shown later, high $\Delta T$ thermal cycle always led to protrusion of $\mathrm{Cu}$. At high temperatures, creep and/or plasticity are activated, leading to significant stress relaxation in $\mathrm{Cu}$. Also, interfacial sliding rates are very high at high temperatures, leading to substantial length difference between $\mathrm{Cu}$ and $\mathrm{Si}$. Besides protrusion of $\mathrm{Cu}$, annealing also resulted in $\mathrm{Cu}$ grain growth and relaxation of residual stresses in $\mathrm{Cu}$. Cross-sectional images of samples revealed insignificant change in the characteristics (size, number, and preferred area of distribution) of cavities or pores in the $\mathrm{Cu}$ due to the annealing.

Figure $4 \mathrm{~b}, \mathrm{c}$ shows the effect of small $\Delta T$ thermal cycling on an annealed sample. Following small $\Delta T$ thermal cycling, $\mathrm{Cu}$ protrudes further out relative to $\mathrm{Si}$. $\mathrm{Cu}$ continues to protrude out relative to $\mathrm{Si}$, albeit at a slower rate, even after 120 small $\Delta T$ thermal cycles. Hence, a transition from intrusion of $\mathrm{Cu}$ to protrusion of $\mathrm{Cu}$ under an identical small $\Delta T$ thermal cycling condition occurred following the annealing treatment. This transition is attributed to the reduction in the residual stresses in $\mathrm{Cu}$ following annealing, and a rationale for such a transition will be presented later with the help of the previously outlined model.

As shown in Figs. 6 and 7, protrusion of $\mathrm{Cu}$ relative to $\mathrm{Si}$ was also observed in both annealed and nonannealed samples during large $\Delta T$ thermal cycling conditions. Figure 8 shows a cross-section of a sample after three large $\Delta T$ thermal cycles, near the extremities of the $\mathrm{Cu}$, where the interfacial shear stresses due to CTE mismatch are maximum. As revealed by Fig. 8, even the large extent of protrusions of $\mathrm{Cu}$, which were observed during high $\Delta T$ thermal cycling, did not cause fracture of $\mathrm{Cu} / \mathrm{Si}$ interface, and the $\mathrm{Cu}$ protrusions were entirely due to the diffusion-assisted interfacial sliding at the $\mathrm{Cu} / \mathrm{Si}$ interface. Protrusion of $\mathrm{Cu}$ relative to $\mathrm{Si}$ during large $\Delta T$ thermal cycling is analogous to the protrusion of graphite fibers in an Al-based composite during small $\Delta T$ thermal cycling. ${ }^{1}$

Figure 9 shows the effect of the electric current on the extent of the protrusion of $\mathrm{Cu}$ relative to $\mathrm{Si}$. In this electromigration test, the direction of electron flow was parallel to the interfacial shear stress. Comparison of Fig. 7b, c with Fig. 9b, c reveals that the electric current significantly enhanced the extent of protrusion of the $\mathrm{Cu}$ out of Si. 
(a)
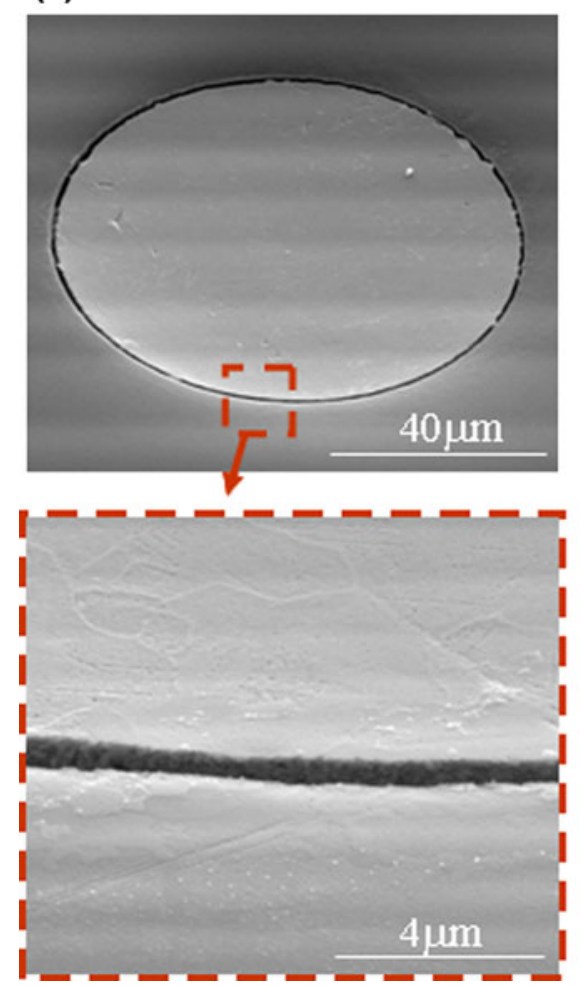

(b)

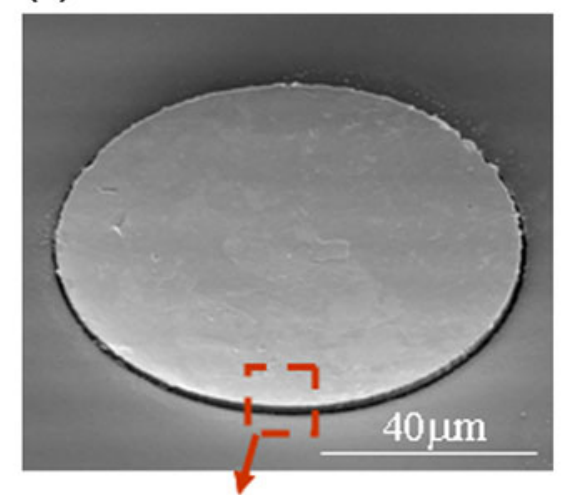

(c)

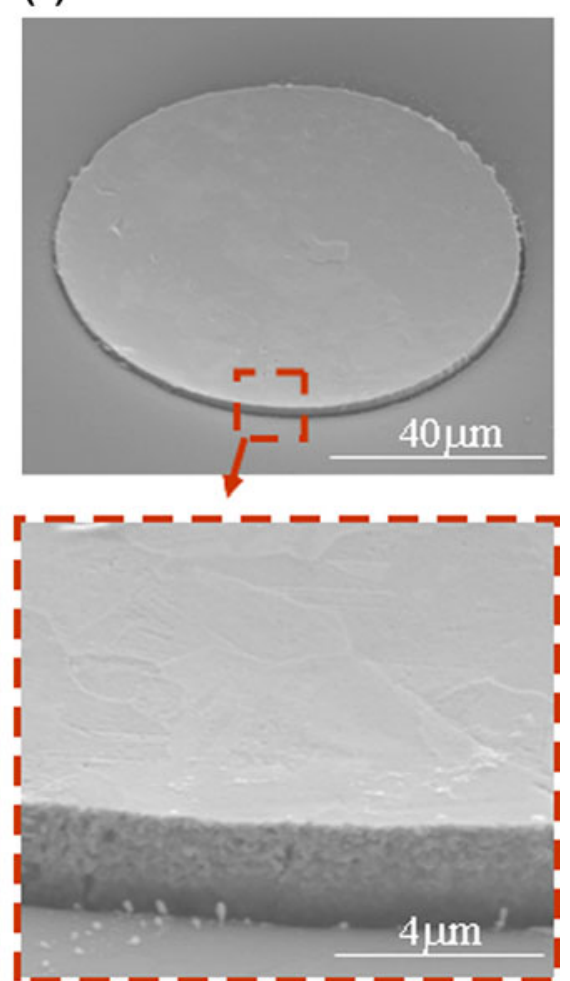

Fig. 7. Effect of large $\Delta T$ thermal cycling on an annealed Cu-filled TSV samples: (a) after annealing at $425^{\circ} \mathrm{C}$ for $30 \mathrm{~min}$, (b) after three cycles between $25^{\circ} \mathrm{C}$ and $425^{\circ} \mathrm{C}$ at $\sim 0.02^{\circ} \mathrm{C} / \mathrm{s}$, and (c) after six cycles between $25^{\circ} \mathrm{C}$ and $425^{\circ} \mathrm{C}$ at $\sim 0.02^{\circ} \mathrm{C} / \mathrm{s}$.

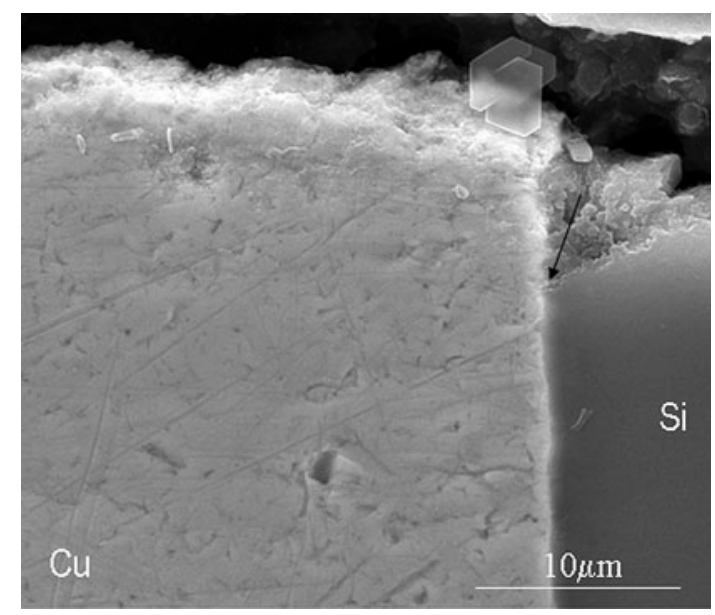

Fig. 8. Cross-sectional micrograph, showing the top edge of the Cu-filled TSVs following annealing at $425^{\circ} \mathrm{C}$ for $30 \mathrm{~min}$, followed by three thermal cycles between $25^{\circ} \mathrm{C}$ and $425^{\circ} \mathrm{C}$. The arrow shows the end $\mathrm{Si}$ at the $\mathrm{Si} / \mathrm{Cu}$ interface.

A quantitative summary of the experimental observation is shown in Fig. 10, and is outlined as follows:

1. For small $\Delta T$ thermal cycling, annealing causes a transition from intrusion of $\mathrm{Cu}$ to protrusion of $\mathrm{Cu}$ relative to $\mathrm{Si}$.

2. For large $\Delta T$ thermal cycling, $\mathrm{Cu}$ protrudes relative to Si irrespective of the annealing condition; however, annealing slows down the extent of protrusion during subsequent thermal cycling.

3. $\mathrm{Cu}$ protrusion during large $\Delta T$ thermal cycling was much larger than that during small $\Delta T$ thermal cycling.

4. With thermal cycling, $\mathrm{Cu}$ continues to protrude (or intrude), although the rate of protrusion (or intrusion) slows down with number of cycles.

5. Protrusion or intrusion of $\mathrm{Cu}$ does not occur due to interfacial fracture but rather occurs due to the diffusion-assisted interfacial sliding.

6. Interfacial sliding due to shear stress is enhanced by electric current (or electromigration) if the electrons flow parallel to the interfacial shear stress.

In the following, a rationale for the above observations will be presented with the help of the previously outlined model. Table I lists the value of several constants used in the calculations.

Figure 11 shows the effect of the interfacial sliding on the calculated strains in $\mathrm{Cu}$ and $\mathrm{Si}$ following one thermal cycle between $250 \mathrm{~K}$ and $410 \mathrm{~K}$, akin to the small $\Delta T$ thermal cycling condition. Figure $11 \mathrm{a}$ shows that, in the absence of interfacial sliding, although there is a finite residual strain after thermal cycling, both $\mathrm{Si}$ and $\mathrm{Cu}$ deform equally, hence precluding any protrusion or intrusion of $\mathrm{Cu}$ relative to $\mathrm{Si}$. On the other hand, $\mathrm{Cu}$ and $\mathrm{Si}$ deform differently in the presence of interfacial sliding, 

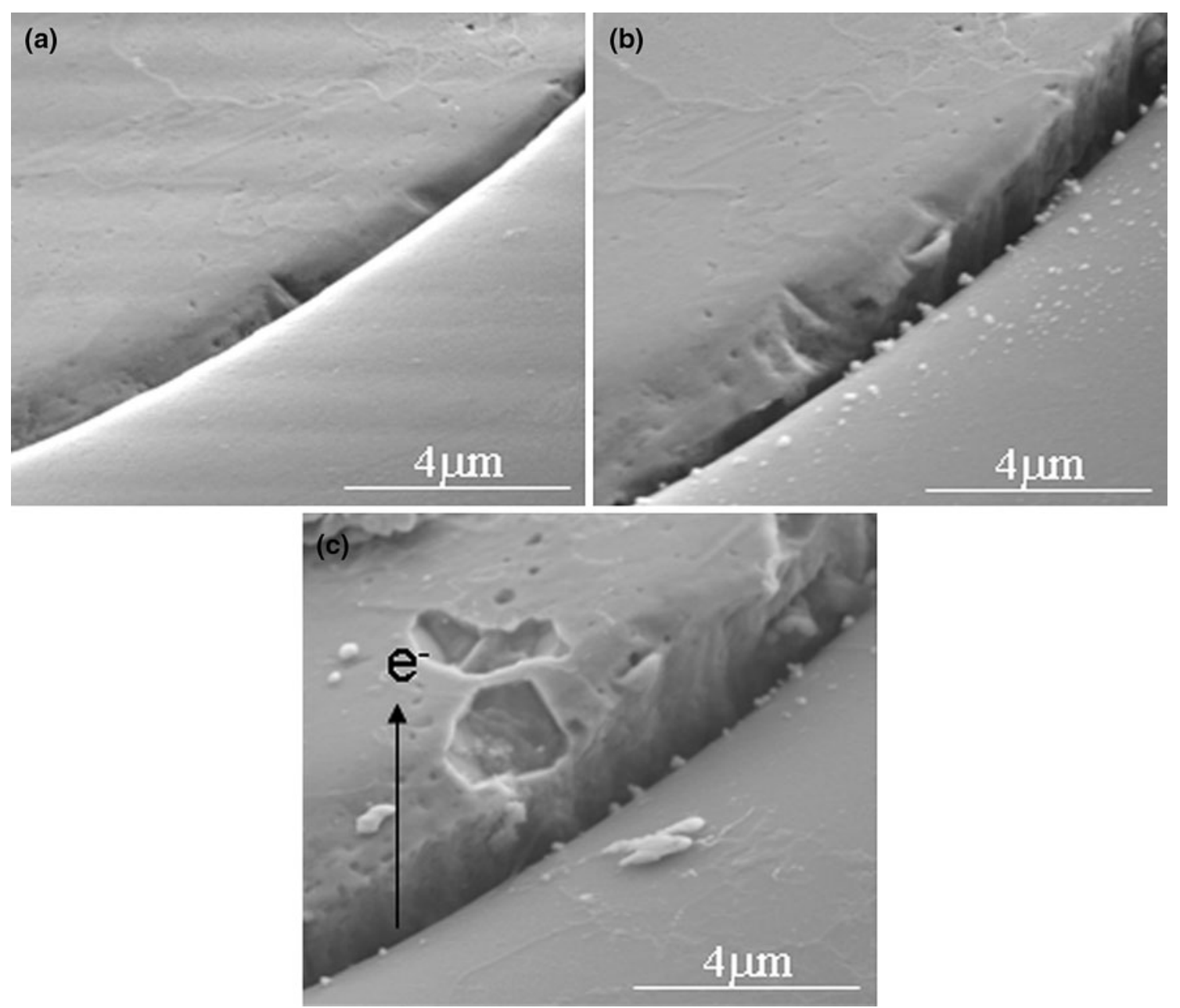

Fig. 9. Effect of large $\Delta T$ thermal cycling and $\mathrm{EM}$ on an annealed Cu-filled TSV samples: (a) as-fabricated, (b) after annealing at $425^{\circ} \mathrm{C}$ for $30 \mathrm{~min}$ and three cycles between $25^{\circ} \mathrm{C}$ and $425^{\circ} \mathrm{C}$ at $\sim 0.02^{\circ} \mathrm{C} / \mathrm{s}$, and (c) after six cycles between $25^{\circ} \mathrm{C}$ and $425^{\circ} \mathrm{C}$ at $\sim 0.02^{\circ} \mathrm{C} / \mathrm{s}$ with the last three cycles with electrons flowing in upward direction (as shown by arrow). The current density was $5.22 \times 10^{4} \mathrm{~A} / \mathrm{cm}^{2}$.
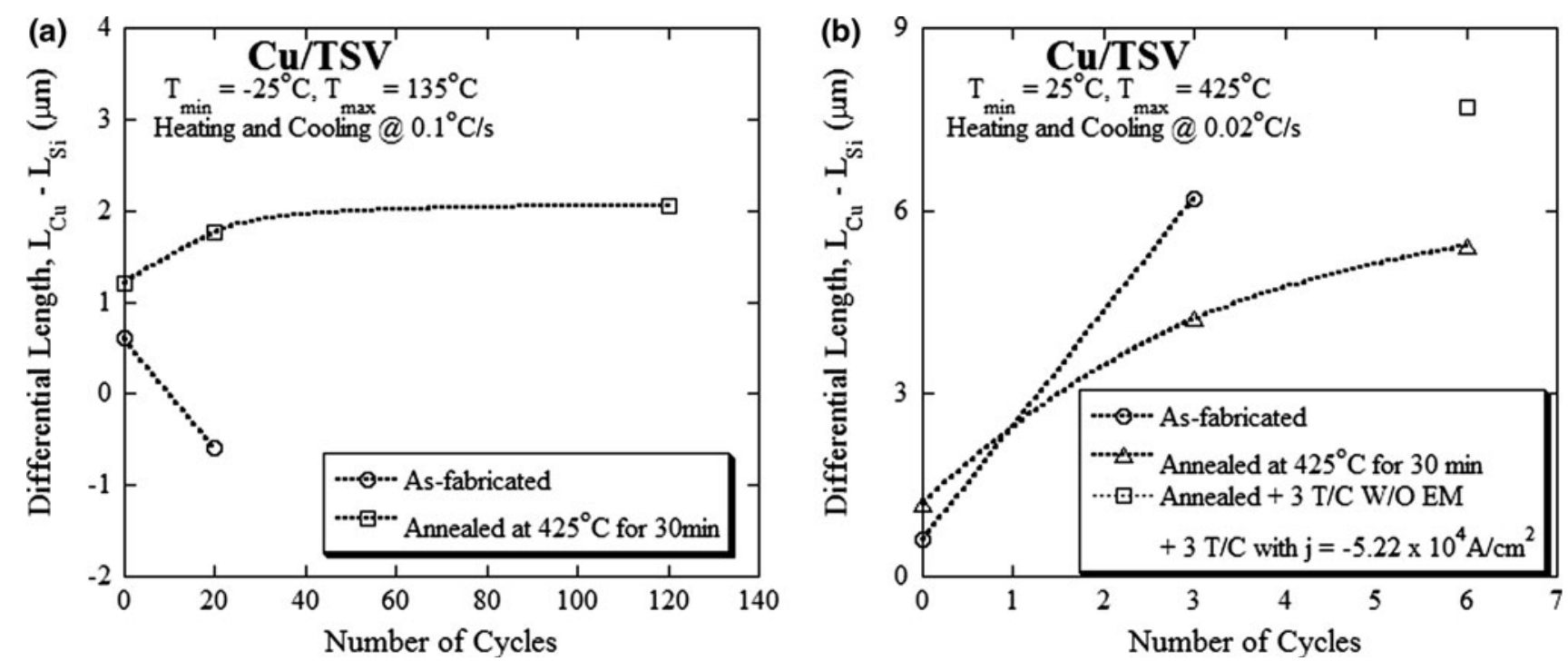

Fig. 10. Quantitative summary of the experimental observations, as shown by Figs. 3-9. (a) Small $\Delta T$ thermal cycling, and (b) large $\Delta T$ thermal cycling. 
Table I. Properties and constants used in calculation

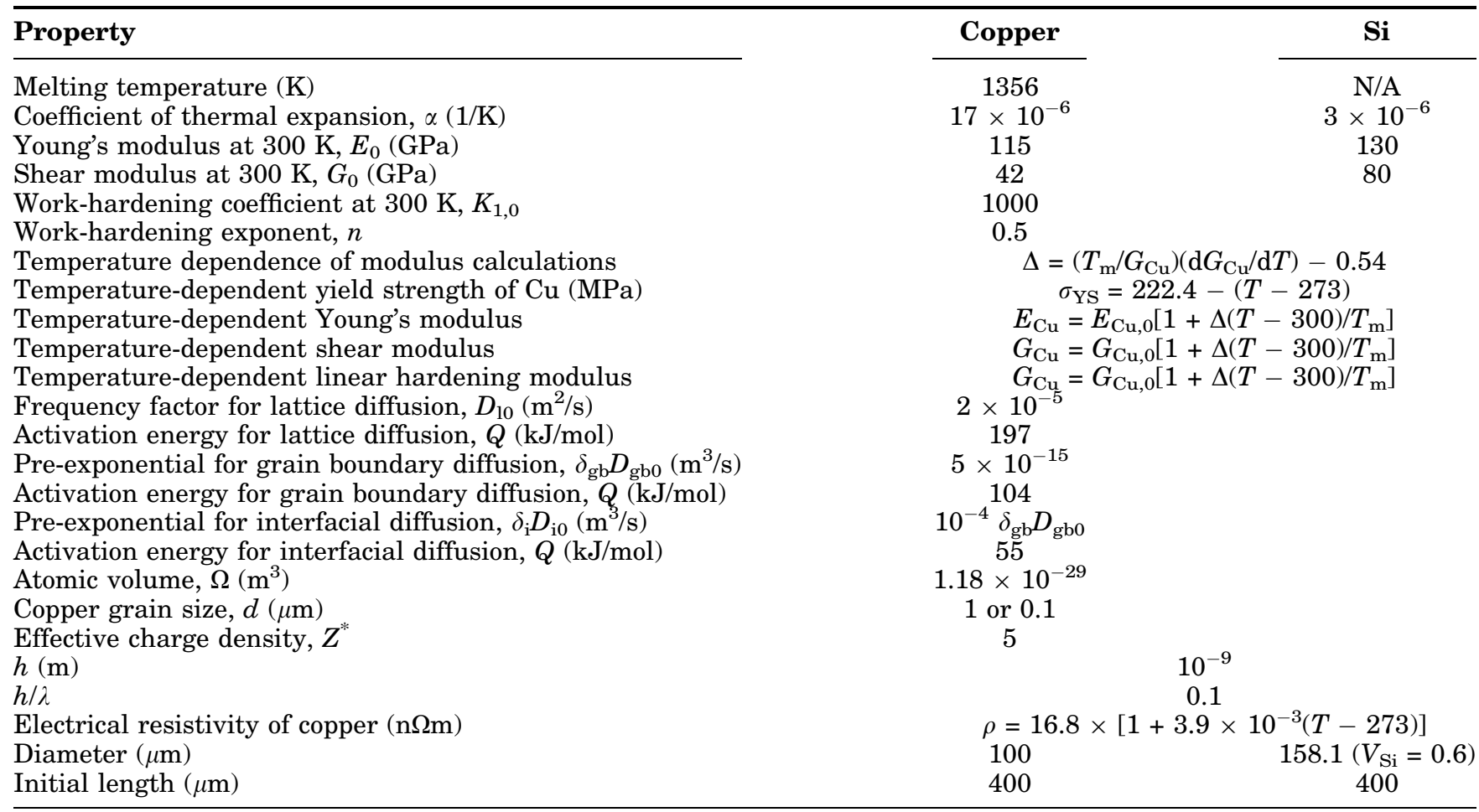

leading to a finite length difference between $\mathrm{Cu}$ and $\mathrm{Si}$ at the end of a thermal cycle. The differential length change (defined as $L_{\mathrm{Cu}}-L_{\mathrm{Si}}$ ) or differential strain (defined as $\varepsilon_{\mathrm{Cu}}-\varepsilon_{\mathrm{Si}}$ ) between $\mathrm{Cu}$ and $\mathrm{Si}$ causes protrusion or intrusion of one relative to another. Another interesting phenomenon, as revealed by Fig. 11, is that the residual differential strain or differential length (as shown in Fig. 11c) per cycle diminishes with number of cycles, implying that the rate of protrusion (or intrusion) of $\mathrm{Cu}$ relative to $\mathrm{Si}$ will slow down with number of cycles. This is consistent with the experimental observations, as reported in Fig. 10. Also, a comparison of Figs. 10a (for annealed sample*) and 11c reveals that the first-principles model adopted in this study is able to predict the differential length change with acceptable accuracy, further proving that the adopted model is able to capture the underlying physics of the problem.

Figure 12 shows the variation in the axial stress in $\mathrm{Cu}$ with temperature change during a small $\Delta T$ thermal cycle. As the temperature increases, $\mathrm{Cu}$ expands more relative to $\mathrm{Si}$ due to its higher CTE and hence starts to build up compressive stress. With temperature, the stress state in $\mathrm{Cu}$ changes from tensile to compressive, and then at high temperatures where either the compressive stress becomes large enough to cause plasticity in $\mathrm{Cu}$ or

*The as-fabricated sample, which showed intrusion of $\mathrm{Cu}$ relative to $\mathrm{Si}$, is explained in a later section. creep becomes significant, the stress in $\mathrm{Cu}$ starts to relax, forming a distinct knee in the stress profile. During cooling, $\mathrm{Cu}$ contracts more rapidly than $\mathrm{Si}$, and the accumulation of tensile stress in $\mathrm{Cu}$ begins. Finally, a finite residual stress, which is different from the initial stress, is accumulated in $\mathrm{Cu}$, resulting in a stress hysteresis loop. During this process, except for thermal strains, finite residual creep, plastic and elastic strains are accumulated in $\mathrm{Cu}$. Unless the distinct knee in the stress (or strain) profile is formed, a finite residual strain in $\mathrm{Cu}$ or $\mathrm{Si}$ at the end of the thermal cycle is not possible. The presence of interfacial sliding allows $\mathrm{Si}$ and $\mathrm{Cu}$ to accumulate different amounts of total strain, leading to a finite differential strain.

Figure 13 shows the effect of higher initial residual stress in $\mathrm{Cu}$ on the residual strains in $\mathrm{Cu}$ and $\mathrm{Si}$ during a thermal cycle. Due to annealing, the residual stress in $\mathrm{Cu}$ reduces and hence samples with high and low initial tensile residual stresses in $\mathrm{Cu}$ qualify as as-fabricated (or nonannealed) and annealed samples, respectively. A comparison of Figs. $11 \mathrm{~b}$ and $13 \mathrm{a}$ reveals that a sample with smaller initial tensile residual stress (akin to annealed sample) shows protrusion of $\mathrm{Cu}$ relative to Si whereas a sample with higher initial residual stress (akin to as-fabricated sample) shows intrusion of $\mathrm{Cu}$ relative to $\mathrm{Si}$ during the small $\Delta T$ thermal cycling condition. These predictions are consistent with the experimental observations, as shown in Figs. 3 and 4 and summarized in Fig. 10. 

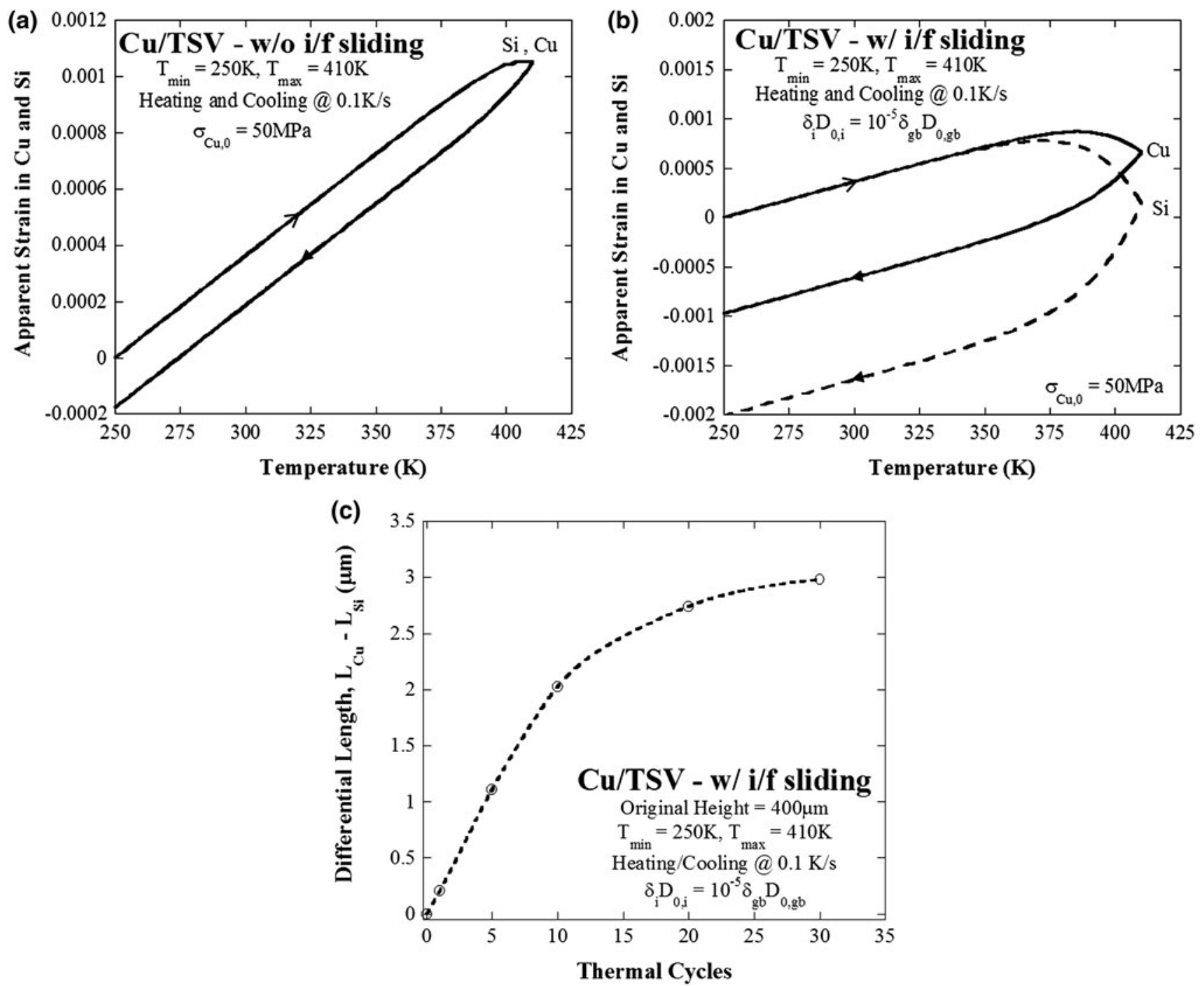

Fig. 11. Model run showing the effect of interfacial sliding over a thermal cycle (a) without interfacial sliding (w/o i/f), (b) with interfacial sliding $(\mathrm{w} / \mathrm{i} / \mathrm{f})$, and $(\mathrm{c})$ the evolution in the differential length between $\mathrm{Cu}$ and $\mathrm{Si}$ with number of cycles.

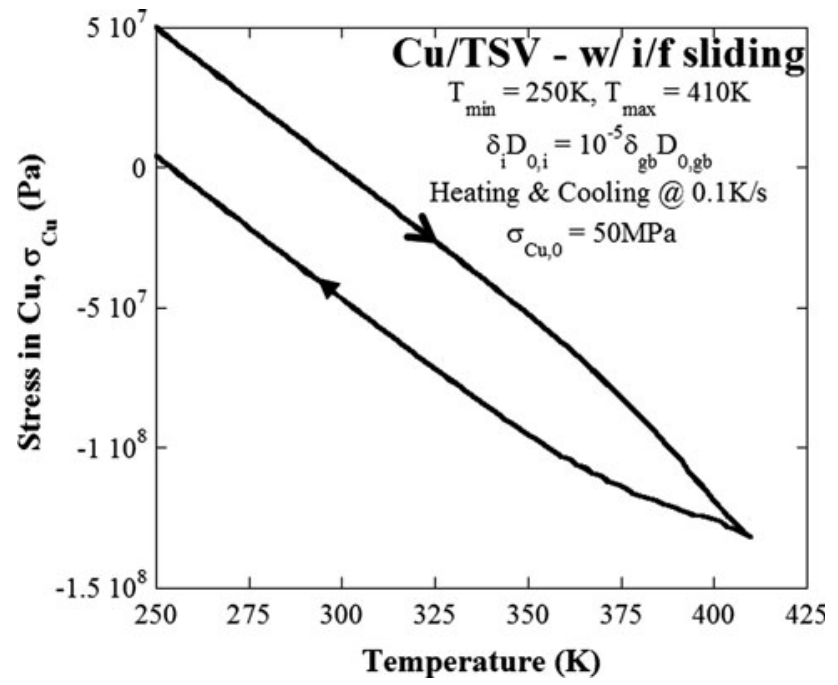

Fig. 12. Model run showing the variation in the axial stress in $\mathrm{Cu}$ during thermal cycling.
Figure $13 \mathrm{~b}$ shows that the $\mathrm{Cu}$ will continue to intrude (or extrude) relative to $\mathrm{Si}$ with increasing number of thermal cycles; however, consistent with the experimental results, the rate of intrusion (or extrusion) will slow down with number of cycles.

Figure 14a shows the effect of the temperature range on the strain variation in $\mathrm{Si}$ and $\mathrm{Cu}$ during a thermal cycle. Consistent with the experimental results, the differential residual strain significantly increases as the $\Delta T$ during a thermal cycle is increased. This is attributed to the longer span of the region after the knee formation in the stress profile, which results in larger difference in the residual stress (and hence residual strain) following a thermal cycle. Figure 14b shows the effect of initial residual stress in $\mathrm{Cu}$ during a large $\Delta T$ thermal cycle. During a large $\Delta T$ thermal cycle, a larger initial residual tensile stress results in smaller residual strains in $\mathrm{Cu}$ and $\mathrm{Si}$ as well as a smaller 

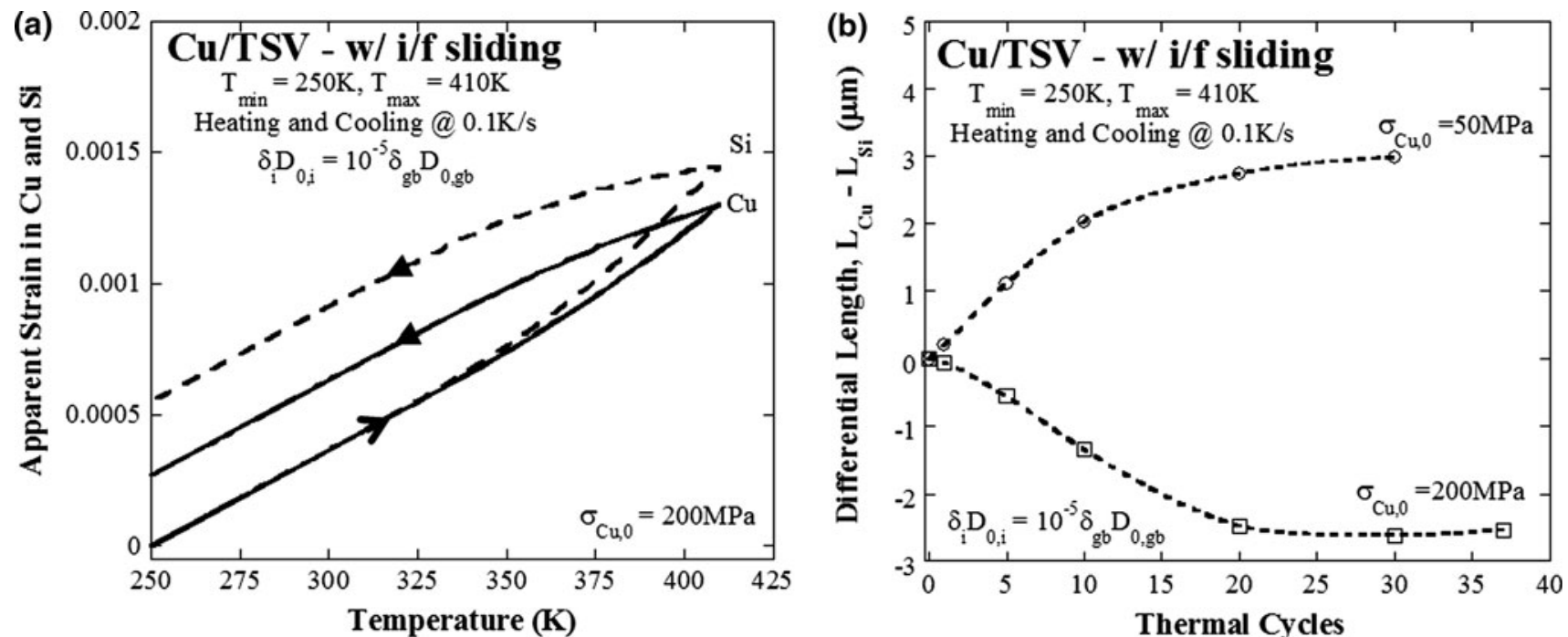

Fig. 13. (a) Model run showing the effect of high residual stress, akin to nonannealed condition, during small $\Delta T$ thermal cycling, and (b) variation in the differential height with number of cycles for low and high residual stress.
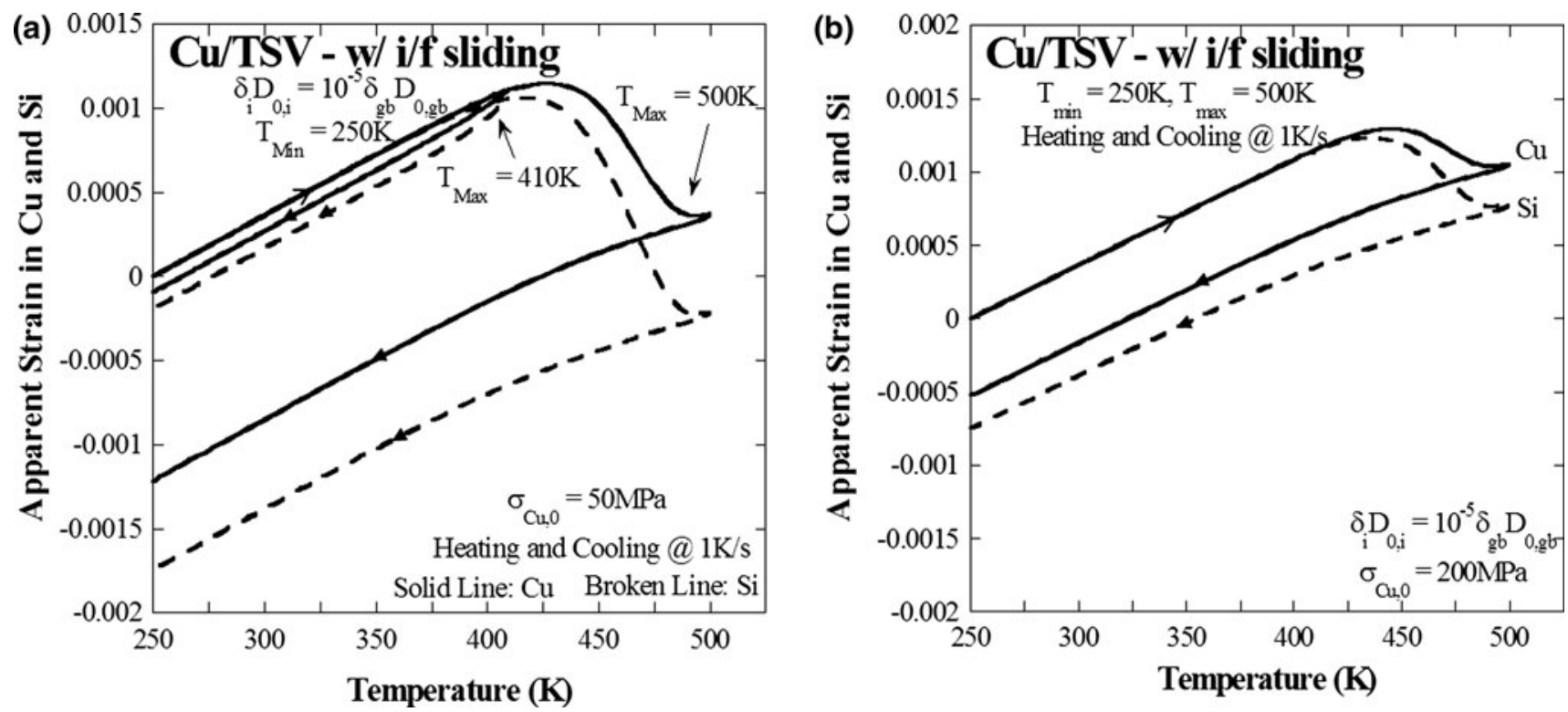

Fig. 14. Model run showing the (a) effect of temperature range and (b) residual stress during large $\Delta T$ thermal cycling.

differential strain; however, no transition from protrusion of $\mathrm{Cu}$ to its intrusion relative to $\mathrm{Si}$ occurred. These two observations are consistent with the experimental results. Based on the model, an initial residual stress of $\sim 230 \mathrm{MPa}$ will cause a transition from protrusion of $\mathrm{Cu}$ to its intrusion for the $\Delta T$ used for the calculations shown in Fig. 14.** This stress is close to the yield strength of $\mathrm{Cu}$ $(\sim 240 \mathrm{MPa})$, and it is unlikely that such a transition will take place during large $\Delta T$ thermal excursions.

\footnotetext{
**The value of critical initial residual stress in $\mathrm{Cu}$ required for a transition from protrusion of $\mathrm{Cu}$ to its intrusion increases with the $\Delta T$ of the thermal cycle.
}

Figure 15 shows the effect of electromigration on the extent of protrusion or intrusion of $\mathrm{Cu}$ relative to $\mathrm{Si}$. Consistent with the experimental results, the protrusion of $\mathrm{Cu}$ relative to $\mathrm{Si}$ is enhanced if the flow of electrons is parallel to the interfacial shear stress. On the other hand, the protrusion becomes lesser if the electrons flow in the direction opposite to the shear stress. Figure $15 \mathrm{~b}$ shows the effect of electromigration on the evolution in the differential length of $\mathrm{Cu}$ and $\mathrm{Si}$ with number of cycles. The effect of the interfacial shear stress alone on the protrusion (or intrusion) of $\mathrm{Cu}$ relative to $\mathrm{Si}$ saturates as the number of cycles is increased; however, in the presence of electromigration, the protrusion 

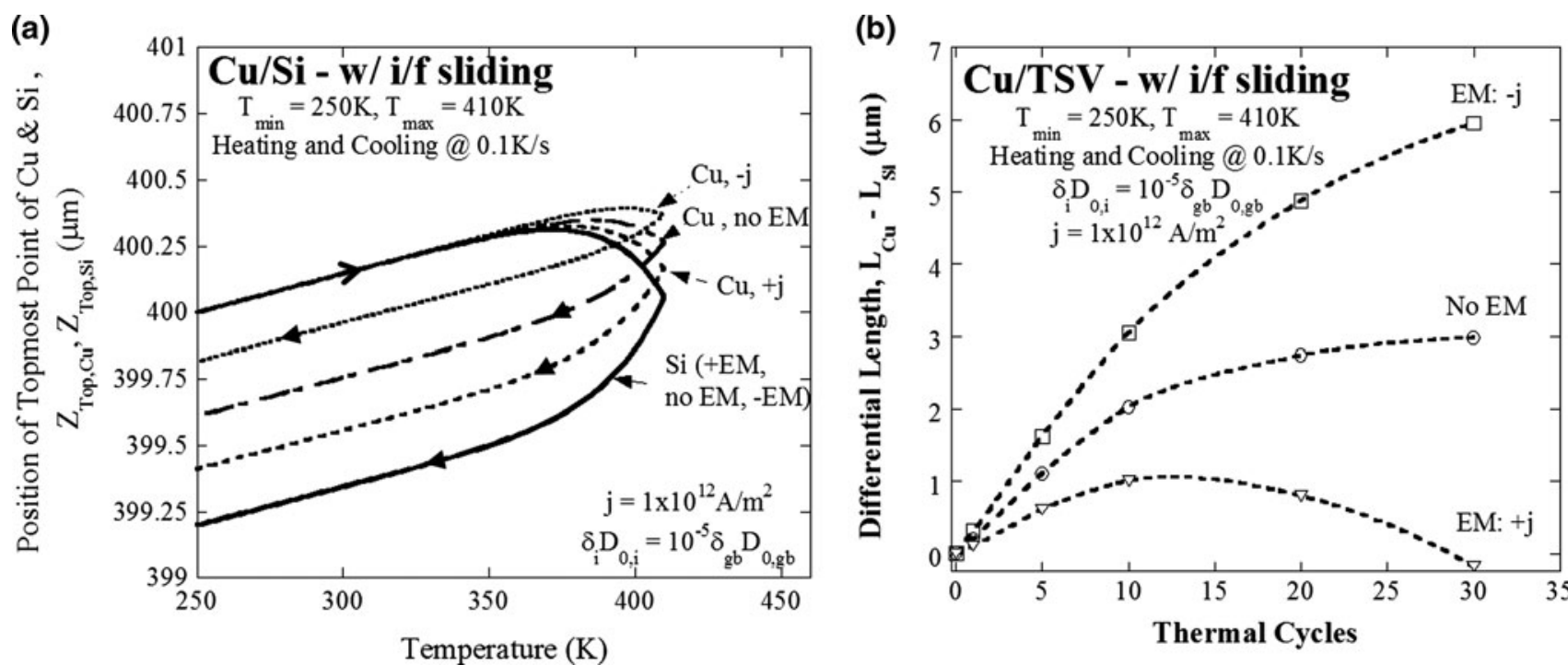

Fig. 15. Model run showing the effect of electromigration on: (a) the position of the topmost point of $\mathrm{Cu}$ and Si during a thermal cycle, and (b) the relative difference in the length of $\mathrm{Cu}$ and $\mathrm{Si}$ with number of cycles.
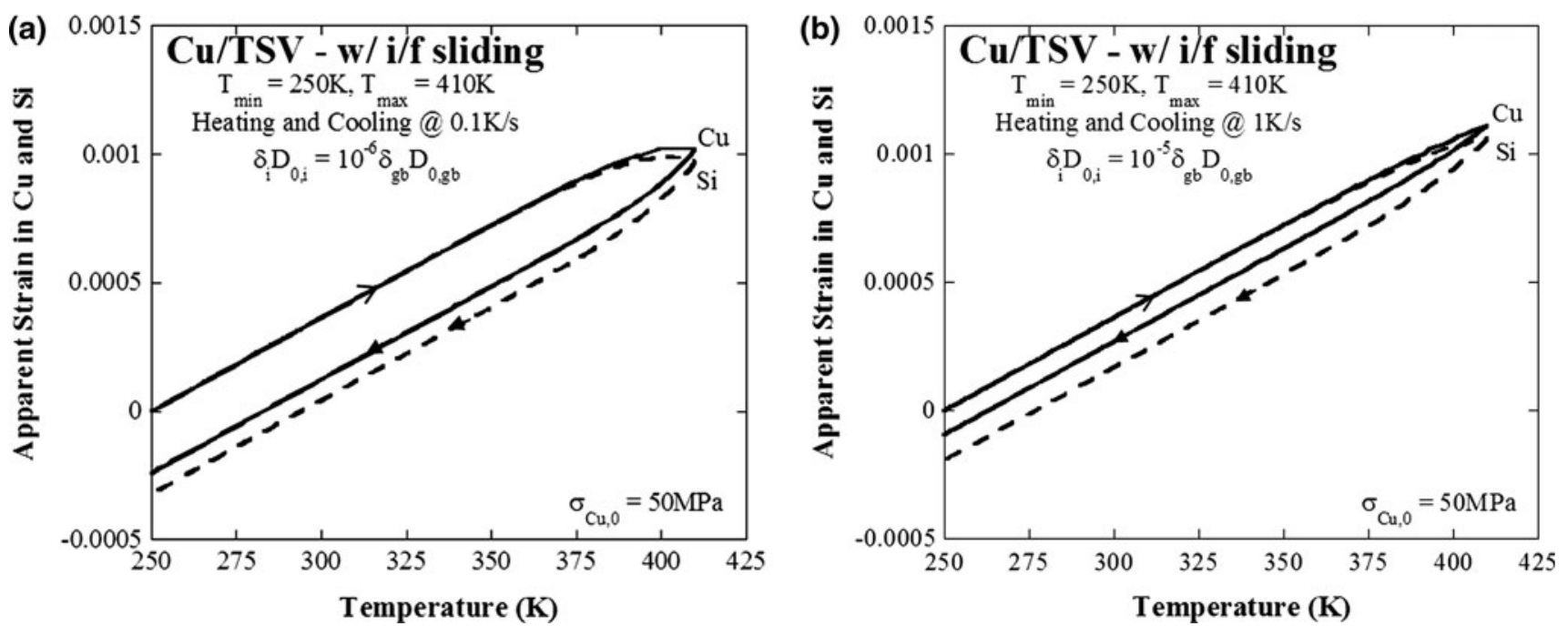

Fig. 16. Model run showing the effects of (a) a slower interfacial diffusion kinetics as compared with Fig. 11a and (b) a faster heating and cooling rate as compared with Fig. 11a, on strains in $\mathrm{Cu}$ and Si during thermal cycling.

(or intrusion) of $\mathrm{Cu}$ relative to $\mathrm{Si}$ does not saturate. Once the effect of the interfacial shear stress saturates, the electromigration dominates the protrusion or intrusion of $\mathrm{Cu}$ relative to $\mathrm{Si}$. It is also interesting to note that an initial protrusion of $\mathrm{Cu}$ may be "forced" to become an intrusion if electric current is passed for a sufficiently long period. Since the length of $\mathrm{Cu}$ and $\mathrm{Si}$ is not affected by the electromigration, the effect of electromigration on the stress state of $\mathrm{Cu}$ and $\mathrm{Si}$ is insignificant.

Two more important parameters, for which experimental results are not available, can be predicted using the developed model, namely (i) the effect of interfacial kinetics, ${ }^{\dagger}$ and (ii) the heating and cooling rate. ${ }^{*}$ Comparison of Fig. $11 \mathrm{~b}$ with Fig. 16a, b reveals the effects of interfacial kinetics and the heating and cooling rate, respectively, on the residual strains in $\mathrm{Cu}$ and $\mathrm{Si}$ during a thermal cycle. With an increase in the interfacial kinetics, the residual strains in $\mathrm{Cu}$ and $\mathrm{Si}$ as well as the

${ }^{\dagger}$ Depending on the electroplating technique and the liner layer, the interfacial kinetics may change.

tDepending on the application of a microelectronic device, the heating and cooling rate during thermal cycling will change. 
differential residual strains between $\mathrm{Cu}$ and $\mathrm{Si}$ increase. On the other hand, a slow cooling and heating rate also lead to larger residual strains in $\mathrm{Cu}$ and $\mathrm{Si}$ as well as larger differential strains. This is attributed to the larger time available for creep and interfacial sliding to occur.

\section{CONCLUSIONS}

Thermal cycling experiments on Cu-filled TSVs for two different $\Delta T$ ranges and for two different initial residual stresses in $\mathrm{Cu}$ were conducted. Thermal cycling caused sliding at the $\mathrm{Cu} / \mathrm{TSV}$ interface, leading to protrusion or intrusion of $\mathrm{Cu}$ relative to $\mathrm{Si}$ without interfacial fracture. The rate of protrusion (or intrusion) slowed down with increasing number of cycles. Annealing caused small protrusion of $\mathrm{Cu}$ without causing interfacial fracture. Furthermore, annealing caused a transition from intrusion of $\mathrm{Cu}$ to its protrusion during small $\Delta T$ thermal cycling. However, $\mathrm{Cu}$ always protruded relative to $\mathrm{Si}$ if the thermal cycling temperature range was increased. Protrusion (or intrusion) of $\mathrm{Cu}$ can be increased, decreased or reversed with application of an electric current. Moreover, the differential residual strain between $\mathrm{Cu}$ and $\mathrm{Si}$ per cycle did not show any saturation with number of cycles if an electric current was constantly passed. The residual differential strain between $\mathrm{Cu}$ and $\mathrm{Si}$ per cycle increases for: (a) high temperature range, (b) slow heating and cooling rates, (c) high interfacial diffusion kinetics, and (d) low initial residual stress in $\mathrm{Cu}$.

\section{ACKNOWLEDGEMENT}

This work was supported by the National Science Foundation, Division of Materials Research, under Grant \# DMR-0513874.

\section{REFERENCES}

1. I. Dutta, Acta Mater. 48, 1055 (2000).

2. I. Dutta, S. Mitra, and A.D. Wiest, Residual Stresses in Composites, ed. E.V. Barrera and I. Dutta (Warrendale: TMS-AIME, 1993).

3. I. Dutta, C. Park, K.A. Peterson, J. Vella, and D. Pan, IEEE Trans. CPMT 28, 397 (2005).

4. C. Park, I. Dutta, K.A. Peterson, and J. Vella, J. Electron. Mater. 32, 1059 (2003)

5. I. Dutta, C. Park, and J. Vella, Mater. Sci. Eng. A 421, 118 (2006).

6. I. Dutta, M.W. Chen, K. Peterson, and T. Shultz, J. Electron. Mater. 30, 1537 (2001).

7. S. Ryu, K. Lu, X. Zhang, J. Im, P. Ho, and R. Huang, IEEE Trans. Dev. Mater. Rel. 11, 43 (2010).

8. Y. Yang, R. Labie, F. Ling, C. Zhao, A. Radisic, J.V. Olmen, Y. Travaly, B. Verlinden, and I. De Wolf, Microelectron. Reliab. 50, 1636 (2010).

9. C. Okoro, R. Labie, K. Vanstreels, A. Franquet, M. Gonzalez, B. Vandevelde, E. Beyne, D. Vandepitte, and B. Verlinden, J. Mater. Sci. 46, 3868 (2011).

10. R. Nagarajan, I. Dutta, J.V. Funn, and M. Esmele, Mater. Sci. Eng. A 259, 237 (1999).

11. J.V. Funn and I. Dutta, Acta Mater. 47, 149 (1999).

12. K.A. Peterson, I. Dutta, and M.W. Chen, Acta Mater. 51, 2831 (2003).

13. M.W. Chen and I. Dutta, Appl. Phys. Lett. 77, 4298 (2000).

14. P. Kumar and I. Dutta, Acta Mater. 59, 2096 (2011).

15. N. Khan, V.S. Rao, S. Lim, H.S. We, V. Lee, X. Zhang, E.B. Liao, R. Nagarajan, T.C. Chai, V. Krispesh, and J.H. Lau, IEEE Trans. Compon. Packag. Technol. 33, 3 (2010).

16. I. De Wolf, International reliability physics symposium (Garden Groves, CA, IEEE 2010), p. 1. 